\title{
Calls Produced by Ecotype C Killer Whales (Orcinus orca) Off the Eckström Iceshelf, Antarctica
}

\author{
Elena Schall and Ilse Van Opzeeland \\ Ocean Acoustics Lab, Alfred Wegener Institute for Polar and Marine Research, Bremerhaven, Germany \\ E-mail: ilse.van.opzeeland@awi.de
}

\begin{abstract}
Killer whales (Orcinus orca) are highly social top predators distributed throughout the world's oceans. They are divided into different ecotypes according to foraging specializations, phenotype, and social organization. For Northern Hemisphere killer whale ecotypes, acoustic behaviour has been shown to relate to foraging strategies and social organization. In contrast to the intensively studied Northern Hemisphere ecotypes, distribution patterns, social structures, and acoustic behaviour of the Southern Hemisphere killer whale ecotypes are poorly known. One of the Southern Hemisphere ecotypes, the Antarctic Ecotype C killer whale, is known to occur in regions with dense pack ice. The limited accessibility of these areas make passive acoustic monitoring (PAM) methods a very effective investigation tool to derive information on ecotype-specific abundance and distribution. During 2 d in February 2013, it was possible to collect concurrent visual and acoustic information of Ecotype $\mathrm{C}$ killer whales off the Antarctic continent. From these events, a call type catalogue was compiled. The 2,238 examined calls were subjectively classified into 26 discrete call types. Ten percent of the examined calls were re-classified by two additional independent observers to examine robustness of the classification. Mean classification accordance among observers was $68 \%$. Most call types were composed of more than one call part. Sixty-five percent of all call types were monophonic, and $35 \%$ were biphonic. Almost two-third of all call types started with a short, broadband pulse. The variability within call types was relatively high. The Ecotype $\mathrm{C}$ vocal repertoire contained typical acoustic features such as biphonation, high call complexity, and generally high variability in frequency modulation. For future studies, the distinct characteristics of some of the call types described herein could potentially serve as acoustic markers for PAM-based differentiation of killer whale ecotypes in the Southern Ocean.
\end{abstract}

Key Words: killer whale, Orcinus orca, vocal behaviour, ecotype, passive acoustic monitoring, Antarctic, Southern Ocean

\section{Introduction}

Knowledge of marine mammal spatio-temporal patterns in distribution and habitat usage lies at the heart of effective management and conservation of populations. To acquire such data on marine mammals in polar regions, passive acoustic monitoring (PAM) using autonomous recording systems provides a particularly versatile tool (e.g., Van Opzeeland et al., 2008; Van Parijs et al., 2009). Data on marine mammal (acoustic) presence can be collected year-round using passive acoustic tools. These data can be collected independently of factors that can severely restrict or even impair visual observation during large portions of the year in many regions of polar oceans such as daylight, weather, and ice conditions. The use of autonomous passive acoustic systems for species-specific monitoring purposes firstly requires knowledge of the types of sounds that the focal species produces to reliably determine when it is (acoustically) present in the vicinity of the recorder. This important baseline information is most reliably obtained from concurrent visual and acoustic observations of the focal species (e.g., Gedamke et al., 2001; McCreery \& Thomas, 2009; Risch et al., 2014).

Killer whales (Orcinus orca) are known to occur throughout the Southern Ocean and, based on sighting information, have been divided into four different ecotypes that differ in morphology, foraging ecology, and habitat preferences (Pitman \& Ensor, 2003). Ecotype A is relatively large in size and has a circum-Antarctic distribution. This ecotype occurs exclusively in open water and feeds mainly on Antarctic minke whales (Balaenoptera bonaerensis) (Pitman \& Ensor, 2003). Ecotype B killer whales occur in regions with loose pack ice, have a circumAntarctic distribution, and are thought to specialize 
in cooperatively hunting Antarctic seals (Pitman \& Ensor, 2003; Pitman et al., 2011). Ecotype C killer whales are the smallest killer whale form known worldwide. They feed mainly on Antarctic fish, such as Antarctic toothfish (Dissostichus mawsoni), and regularly occur in dense pack ice and polynyas (i.e., open water areas in the ocean surrounded by sea-ice) (Pitman \& Ensor, 2003). Type C killer whales seem to range within relatively small-scale regions, comparable to behavioural patterns observed in Northern Hemisphere fish-eating killer whales (Andrews et al., 2008). Recently, a further killer whale morphotype, referred to as Ecotype D, was described for the Southern Hemisphere. This ecotype is thought to occur in sub-Antarctic waters and also most likely feeds on fish (Pitman \& Ensor, 2003).

Given that the different Southern Hemisphere killer whale forms have only been described relatively recently, little is known about their relative distributions and movement patterns (e.g., Andrews et al., 2008; Ainley et al., 2009; Pitman et al., 2011). Autonomous PAM systems are deployed increasingly more often in the Southern Ocean and can be left to record for multiple years (e.g., Śirović et al., 2004; Rettig et al., 2013; Van Opzeeland et al., 2013). These systems provide a potentially highly suitable method to collect broad-scale spatio-temporal information on the distribution of the different killer whale ecotypes, further expanding information to the austral winter and areas with dense ice cover. Such data are currently virtually absent due to the logistic constraints of accessing ice-covered waters. However, it is not yet known whether and to what extent the different killer whale ecotypes in the Southern Hemisphere differ acoustically, a prerequisite to be able to reliably distinguish the ecotypes using passive acoustic records.

To date, only three studies describe Southern Hemisphere killer whale vocal behaviourAwbrey et al. (1982), Richlen \& Thomas (2008), and Wellard et al. (2015) - and at least two of the three were not able to attribute recorded sounds to a specific killer whale ecotype with any certainty. Wellard et al. (2015) analysed recordings of killer whales from the Bremer Canyon in Western Australia and categorized 142 killer whale vocalizations into nine discrete call types (i.e., repeatedly occurring call types with distinct temporal and spectral characteristics), differentiating both burst-pulsed sounds and whistles. The authors report that recorded killer whales displayed phenotypic characteristics concurrent with the mammal-eating Ecotype A. Awbrey et al. (1982) analysed recordings from Antarctic killer whales from Gerlache Strait and McMurdo Sound and found that the typical killer whale pulsed vocalizations were characterized by abrupt shifts in frequency modulation rates. Awbrey et al. also found that in Antarctic killer whales, pronounced harmonics were concentrated at higher frequencies but that the temporal characteristics did not differ from Northern Hemisphere killer whale calls. Richlen \& Thomas (2008) analysed recordings from McMurdo Sound in the Ross Sea and identified seven discrete call types and a large number of aberrant call types (i.e., divergent variants of discrete call types). Based on the large vocal repertoire, high call rates, and similarities in sound structures to Northern Hemisphere fish-eating resident killer whales, Richlen \& Thomas assumed that they recorded the fish-eating Ecotype $\mathrm{C}$ killer whales but were not able to confirm this conclusively as visual data were not concurrently collected.

This study presents a first record of call types produced by a group of visually confirmed Ecotype $\mathrm{C}$ killer whales. The compiled catalogue of pulsed calls, Call Catalogue for Antarctic Ecotype $C$ Killer Whales (included in the Supplementary Materials for this article, which are available on the Aquatic Mammals website: www.aquaticmammalsjournal.org/index.php? option $=$ com_content $\&$ view $=$ article $\& i d=10 \&$ Itemid=147), provides an initial step in exploring whether different killer whale ecotypes in the Southern Hemisphere can be distinguished acoustically.

\section{Methods}

\section{Acoustic and Photographic Data}

The PerenniAL Acoustic Observatory in the Antarctic Ocean (PALAOA) is located at $70^{\circ} 31^{\prime} \mathrm{S}, 8^{\circ} 13^{\prime} \mathrm{W}$ on the Eckström Iceshelf, eastern Weddell Sea coast, Antarctica (Figure 1). Recordings were made with a RESON TC4032 hydrophone deployed at 170-m depth underneath the 100-m-thick floating Antarctic ice shelf through a bore-hole. Distance to the ice shelf edge was $\sim 1 \mathrm{~km}$, and water depth was around $250 \mathrm{~m}$. The hydrophone was connected to a RESON VP2000 amplifier (30 dB gain) and bandpass filter $(10 \mathrm{~Hz}$ to $100 \mathrm{kHz})$. Signals were digitized at $48 \mathrm{kHz} / 16$ bit, encoded to a $192 \mathrm{kBit}$ MP3 stream, and stored locally at Neumayer Base as a sequence of time-stamped files. The MP3 data were shipped to the Alfred-Wegener Institute once a year for in-depth analyses. In addition, the audio was compressed to a $24 \mathrm{kbit} / \mathrm{s}$ OGGVorbis stream and transmitted in near-real time from Neumayer to the Alfred-Wegener Institute in Bremerhaven via a $128 \mathrm{kbit} / \mathrm{s}$ satellite link. The effective bandwidth of the PALAOA recordings was $10 \mathrm{~Hz}$ to $15 \mathrm{kHz}$ (due to the compression 


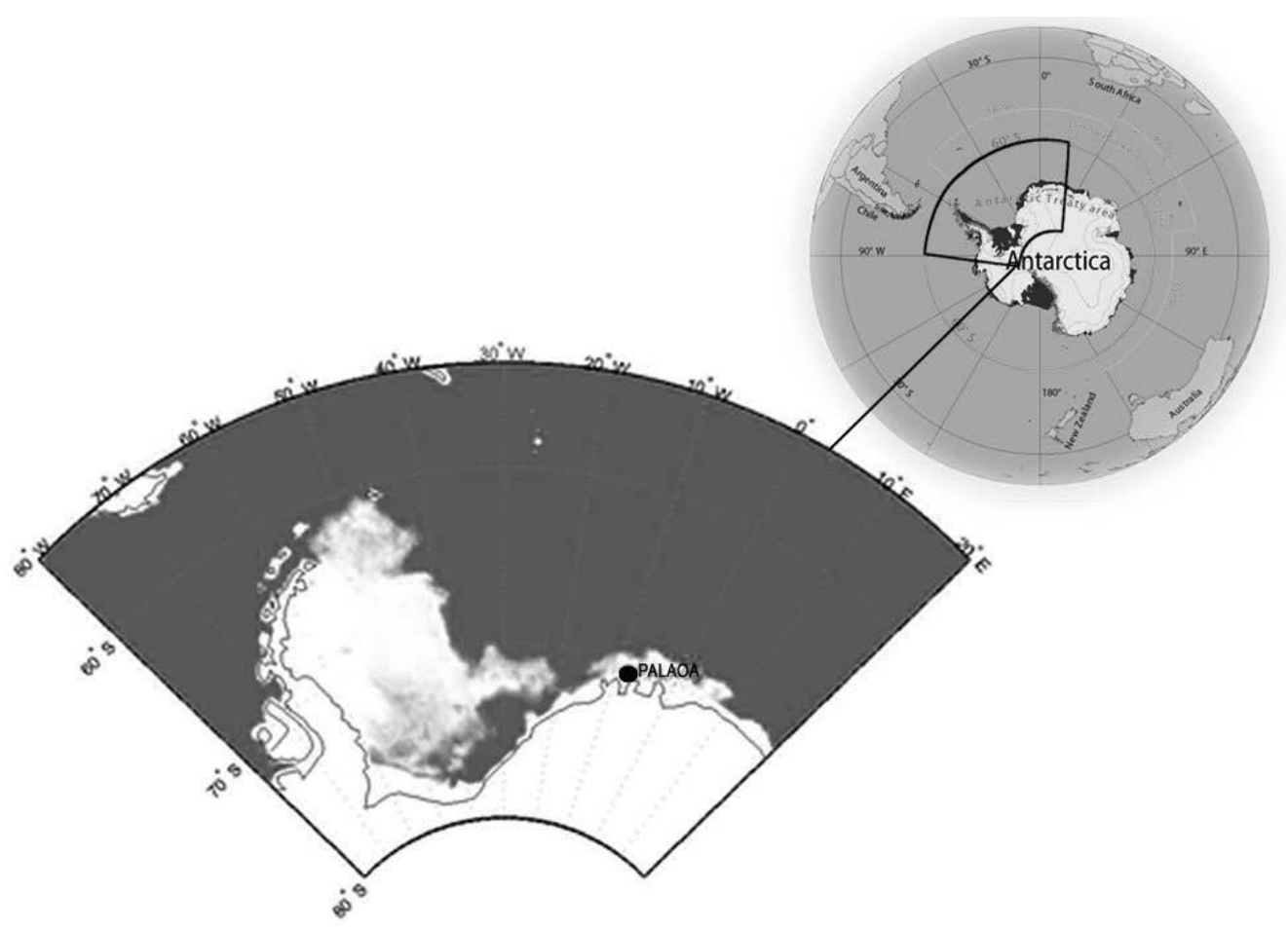

Figure 1. Position of PerenniAL Acoustic Observatory in the Antarctic Ocean (PALAOA) on the Antarctic ice shelf at Atka Bay $\left(70^{\circ} 31^{\prime} \mathrm{S}, 8^{\circ} 13^{\prime} \mathrm{W}\right)$

during transmission), the dynamic range was $\sim 90 \mathrm{~dB}$, with full-scale set manually to values between 138 and $150 \mathrm{~dB}_{\mathrm{FS}}$ (decibels relative to full scale) re $1 \mu \mathrm{Pa}$ to avoid clipping in case of loud conditions (see Klinck et al., 2016, for detailed descriptions of PALAOA's design and set-up). The availability of live satellite-streamed PALAOA data allowed for the inspection of recordings in near-real time.

On 21 and 28 February 2013, killer whale sounds were identified in the live-streamed recordings. On both days, a small group of researchers from Neumayer Base was requested to photographically document a killer whale group that was thought to be present just off the Eckström Iceshelf where PALAOA is located. On both days, a group of at least four killer whales was observed and photographed. Two individuals clearly had larger dorsal fins and were presumably males; whereas the other two individuals were likely females or juveniles. Whether these two encounters comprised the same individual whales could not be reliably assessed. However, it was possible to identify the killer whales as Ecotype $\mathrm{C}$ based on the presence of the typically slanted eyepatch (confirmed by R. L. Pitman; Figure 2). From these 2 d, 231 1-min sound files (distributed throughout different day and night times) were selected for in-depth analyses by visual and aural inspection of the sound files using spectrograms. Files were selected based on the clear presence of killer whale sounds and high levels of killer whale acoustic activity. For the in-depth acoustic analysis of the data, only the higher quality MP3 data were used.

\section{Call Type Classification}

Killer whales are known to produce three main sound types: (1) clicks, (2) whistles, and (3) pulsed calls (e.g., Ford, 1987, 1991). Clicks are short broadband sounds that are used for echolocation as in all other delphinids (Ford, 1989). Whistles are narrowband tonal signals, often exhibiting higher frequencies than pulsed calls (e.g., on average between 5.4 and 9.9 kHz; Ford, 1989). Pulsed calls are broadband sounds, which often display strong harmonics and are characterized by high pulse-repetition rates (Ford, 1989). Pulsed calls are known to exist in reliably classifiable categories (discrete, aberrant, and variable call types) in other killer whale ecotypes (Ford, 1989; Strager, 1995; Deecke et al., 2005; Van Opzeeland et al., 2005). Given that the bandwidth of the analysed recordings was limited (upper frequency limit: 


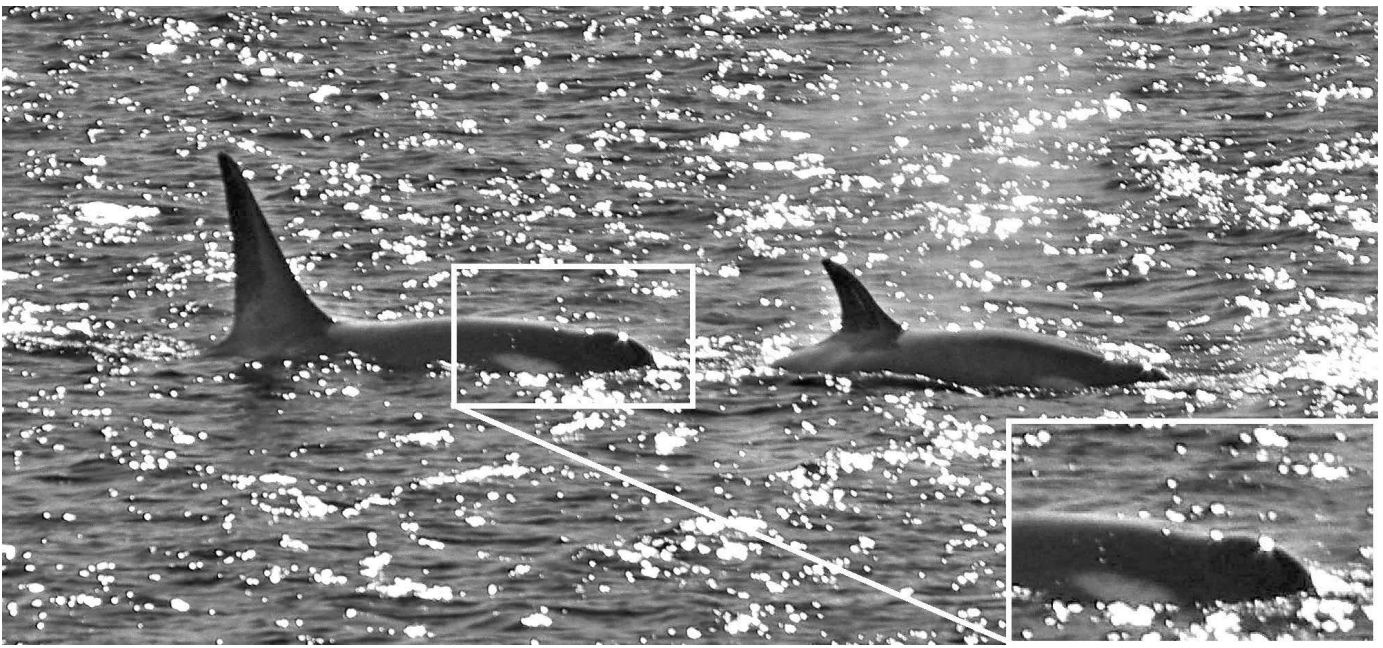

Figure 2. Antarctic killer whales (Orcinus orca) off PALAOA station. This picture was taken on 28 February 2013. Note the distinct slanted eyepatch which characterises Ecotype C killer whales. (Photo by Thedda Hänssler)

$15 \mathrm{kHz}$ ), the classification analyses in this study were restricted to pulsed calls only.

Spectrograms of all killer whale pulsed calls were based on time frames of $c a .5 \mathrm{~s}$ and an FFT size of 1,042 , with resulting frequency and time resolutions of $46.1 \mathrm{~Hz}$ and $21.7 \mathrm{~ms}$, respectively. The spectrograms from the 231 1-min MP3 files were used to aurally and visually classify the killer whale calls contained in these files into different call types using Raven Lite 1.0 (Charif et al., 2006). Killer whale call type classification followed the method used by Ford (1991) and Strager (1995). This method is based on the identification of call segments (call parts) with consistent temporal and spectral characteristics and the recognition of their repeated combinations into discrete call types. Call types can also consist of single call segments, provided that this call segment occurs in its single form repeatedly. Only single-segment and combined (i.e., consisting of more than one call segment) call types that occurred at least five times were included in the Call Catalogue (minimal-occurrence criterion). All killer whale vocalizations that were assigned a call type were attributed a number ranging from 1 to 3 as an indicator of quality ( 1 for very good quality and 3 for poor quality) based on the clarity of the acoustic signature in the spectrogram and the amount of overlap with other calls.

Ten percent of all classified calls were selected randomly (with each call type occurring at least once) from all good quality calls (i.e., having quality indicators 1 or 2) to function as a subset for cross-validation of the classification. Calls that were selected for the subset were marked using the PamguardBeta64_ViewerMode (OGP E\&P
Sound and Marine Life Joint Industry Program) with the "Mark observer" function and saved as an SQL database. This subset was then blindly (without knowing the classification results of the first analyst) cross-validated by two additional independent analysts to evaluate the reliability of the classification.

\section{Acoustic Parameters}

A set of standard acoustic parameters was measured (using the same spectrogram settings as in Raven Lite) with Raven Pro 1.4 (Bioacoustics Research Program, 2011)The acoustic parameters that were measured comprised (1) total duration (ms), (2) duration of distinct segments (ms), (3) minimum frequency $(\mathrm{Hz})$, (4) maximum frequency $(\mathrm{Hz}),(5)$ start frequency $(\mathrm{Hz}),(6) \mathrm{mid}$ frequency $(\mathrm{Hz})$ (defined as the frequency of the call at half its duration), (7) end frequency $(\mathrm{Hz})$, and (8) the frequency of the highest amplitude $(\mathrm{Hz})$ (Figure 3).

For each call type, all good quality calls (quality indicators 1 or 2) were selected for the measurements of acoustic parameters (see above). For call types composed of several call parts (i.e., characterized by short pauses or transitions between sections of the same call), parameters were measured for each call part separately (indicated as P1, P2, $\mathrm{P} 3$, and P4). Not all parameters could be measured when call segments were not of sufficient quality (e.g., due to overlap with other calls), and this precluded reliable power spectral measurements. Some killer whale call types were composed of an overlapping low (LFC) and high (HFC) frequency component, referred to as biphonic calls (Hoelzel \& Osborne, 1986; Filatova et al., 2009). Acoustic 

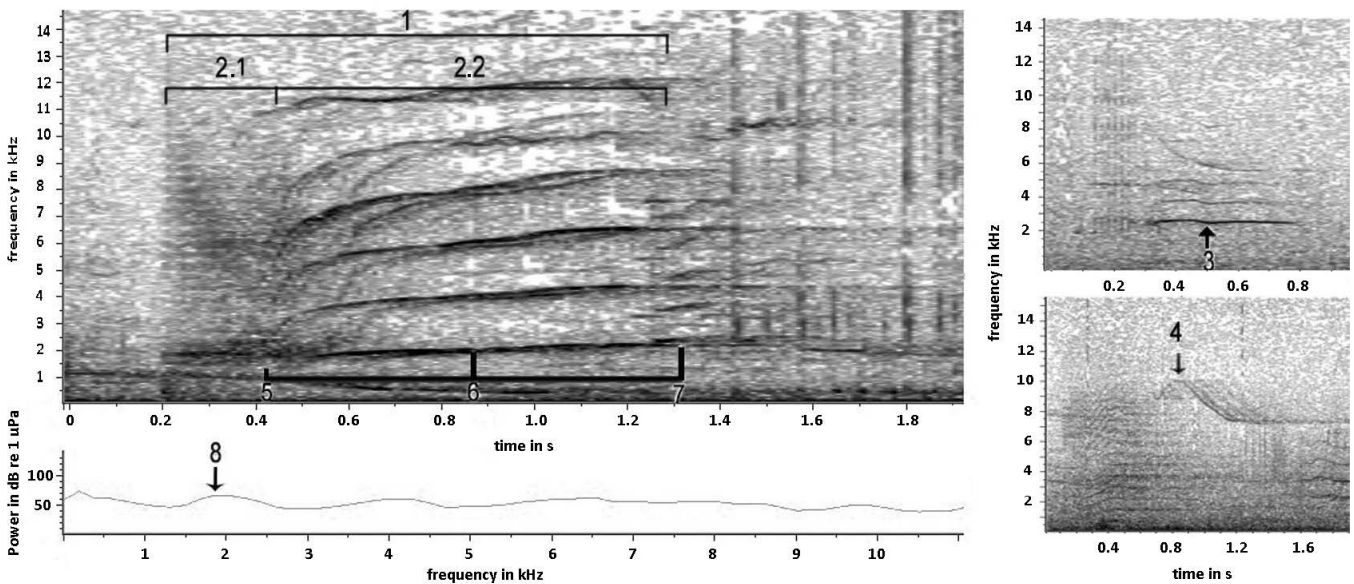

Figure 3. Acoustic parameters shown as examples from three calls produced by Antarctic killer whales. The left picture shows the spectrogram of a call with the respective power spectrum underneath. For this call type, the total duration (1); duration of segments (2); start, (5), mid, (6), and end frequencies (7); and the frequency of highest amplitude (8) were measured. On the right, two exemplary calls for which minimum (3) and maximum (4) frequency were measured are depicted. All three call types contain the typical short broadband pulse in the beginning, which is marked with the number 2.1 within the spectrogram shown on the left-hand side.

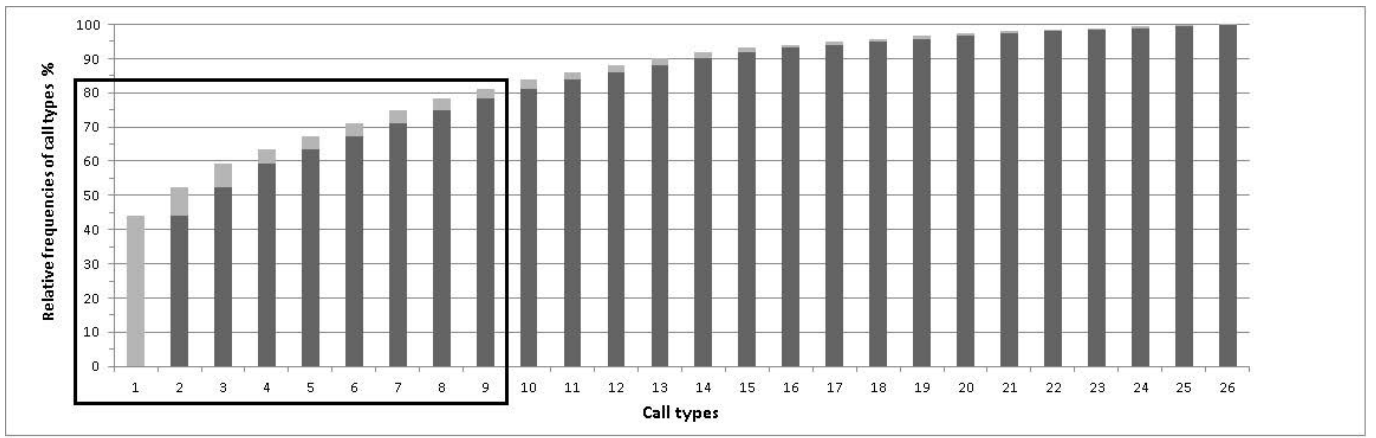

Figure 4. Cumulative frequency representation for all 26 call types from Antarctic killer whales. The black box indicates that $80 \%$ of all classified calls are represented by just nine call types. Light grey bars indicate the relative frequency of each respective call type, and dark grey bars indicate the cumulative frequencies of precedent call types.

parameters were measured separately for both LFC and HFC structures in biphonic calls.

The descriptive statistics for acoustic parameters of each call type comprise mean (Mean), standard deviation (SD), coefficient of variation $(\mathrm{CV})$, the minimal (Min) and maximal value (Max), and the number of the respective measured call parts $(n)$.

\section{Results}

From the $231 \mathrm{~min}$ of recordings that were analysed, a total of 2,276 killer whale calls were examined. Of these, 2,238 calls were grouped into 26 discrete call types of which five are further subclassified into distinct variants (see Call Catalogue,
Supplementary Materials). The remaining 38 calls did not pass the minimal-occurrence criterion and were not classified further. These calls possibly represent variable or aberrant call types or even infrequent discrete call types (see "Additionally Observed Calls" section in the Call Catalogue, Supplementary Materials).

Three of the 26 call types were observed less than 10 times each (1\% of the 2,238 classified calls), while the remaining 23 call types were repeated 10 to 979 times throughout the encounters (99\% of the 2,238 classified calls) (Figure 4). Frequency of occurrence was highly variable among call types, with only nine call types forming $80 \%$ of the vocal repertoire. 
Agreement in call type classification among independent observers was on average $67.6 \%$ (with a minimum of $55.8 \%$ and a maximum of $78.6 \%)$. For each call type, there was at least one agreement in classification between the first analyst (the researcher who analysed the full data set and created the Call Catalogue) and one of the additional independent analysts (Table 1). Interanalyst reliabilities ranged from $25 \%$ (for call type 17; all call types can be found in the Call Catalogue, Supplementary Materials) to $100 \%$ (for call types 4,18, 19,21, and 24) (Table 1). The classification of call types 6,7 , and 17 resulted in inter-analyst reliabilities below 50\%, leaving their status as discrete call types questionable.

Table 1. The inter-analyst reliability for all 26 call types; classification results from two additional independent analysts were checked against the classification of the first analyst.

\begin{tabular}{|c|c|c|}
\hline $\begin{array}{l}\text { Call } \\
\text { type }\end{array}$ & $\begin{array}{l}\text { Inter-analyst } \\
\text { reliability }(\%)\end{array}$ & $\begin{array}{l}N \text { of cross- } \\
\text { checked calls }\end{array}$ \\
\hline 1 & 75.4 & 59 \\
\hline 2 & 84.1 & 22 \\
\hline 3 & 97.9 & 24 \\
\hline 4 & 100.0 & 9 \\
\hline 5 & 53.1 & 16 \\
\hline 6 & 38.9 & 9 \\
\hline 7 & 33.3 & 6 \\
\hline 8 & 70.0 & 10 \\
\hline 9 & 62.5 & 16 \\
\hline 10 & 72.2 & 9 \\
\hline 11 & 75.0 & 4 \\
\hline 12 & 50.0 & 5 \\
\hline 13 & 83.3 & 3 \\
\hline 14 & 75.0 & 4 \\
\hline 15 & 75.0 & 2 \\
\hline 16 & 60.0 & 5 \\
\hline 17 & 25.0 & 2 \\
\hline 18 & 100.0 & 3 \\
\hline 19 & 75.0 & 2 \\
\hline 20 & 75.0 & 4 \\
\hline 21 & 100.0 & 2 \\
\hline 22 & 50.0 & 2 \\
\hline 23 & 50.0 & 1 \\
\hline 24 & 100.0 & 1 \\
\hline 25 & 75.0 & 2 \\
\hline 26 & 75.0 & 2 \\
\hline
\end{tabular}

An alternative classification-for example, call types 6 and 7 being variants of call type 1, and call type 17 being a variant of call type 4 -would be conceivable on the basis of these findings.

The observed call repertoire of 26 discrete call types for Antarctic Ecotype C killer whales comprised 17 monophonic $(65 \%$ of the vocal repertoire) and nine biphonic (35\% of the vocal repertoire) call types. However, biphonic call types were more frequently used, making up $73 \%$ of all examined calls. The majority of the biphonic call types $(89 \%)$ were composed of three parts and started with a short broadband pulse call part (Figure 3). One biphonic call type consisted of four parts (call type 3 ). Monophonic calls often comprised two call parts, also starting with the short broadband pulse (53\% of all monophonic calls). Furthermore, six of the monophonic call types were composed of one part (call types 5, $11,12,13,22$, and 25), one monophonic call type ended with a longer broadband pulse (call type 18) and one monophonic call type was composed of two LFCs (call type 23).

One call type (call type 3 ) was observed to occur in a sequence during which the call was repeated up to 21 times/min over a period of 141 -min files on 21 February 2013 (see Supplementary Figure ES1 in the Supplementary Materials).

\section{Discussion}

The unique opportunity to simultaneously obtain acoustic and visual data allowed confirmation of which killer whale ecotype produced the sounds that were recorded. This provided a first step towards exploring the possibilities for ecotype-specific acoustic monitoring of Antarctic killer whales. It is important to note, however, that this study was based on recordings of a small group of animals, leaving it unknown to what extent the features of acoustic behaviour described herein are representative for Ecotype $\mathrm{C}$ killer whales in general. This stresses the need to collect information on multiple groups of the same ecotype while at the same time extending these studies to the other killer whale ecotypes to explore which features could function as stable ecotype-specific acoustic markers.

\section{Potential Ecotype C-Specific Features of Killer Whale Vocal Behaviour}

While taking into account the limited sample size with respect to the number of individuals and time frame recorded as mentioned above, there are a number of features in the acoustic repertoire described herein that may have the potential to be ecotype-specific and deserve further investigation once additional data become available. 
Repertoire Size-The general repertoire size from the observed group of killer whales of 26 discrete call types was obtained from only $2 \mathrm{~d}$ of recordings. This is a relatively large repertoire compared to the repertoires described for Northern Hemisphere killer whale ecotypes in which the larger vocal repertoires are generally attributed to resident fish-eating populations (typically, $n=7$ to 18; e.g., Ford, 1987; Strager, 1995; Deecke et al., $2005,2011)$. Ecotype $C$ killer whales are known to feed mainly on fish (Pitman \& Ensor, 2003). Their apparently large vocal repertoire, therefore, may possibly provide further support for the idea that the killer whale feeding ecology is an important factor shaping vocal behaviour (e.g., Deecke et al., 2005).

Whether repertoire-size (i.e., per recording day) or individual call rates alone could be used to distinguish the Southern Hemisphere ecotypes acoustically cannot be determined from our dataset. Fish-eating killer whales in the Northern Hemisphere are known to produce sounds in all behavioural states (Barrett-Lennard et al., 1996; Van Opzeeland et al., 2005; Filatova et al., 2013; Holt et al., 2013), whereas mammal-eating killer whales typically restrict sound production to a few specific behavioural contexts, presumably to avoid alerting their acoustically sensitive prey (e.g., Deecke et al., 2005; Riesch \& Deecke, 2011). Southern Hemisphere Ecotypes A and B killer whales both focus on marine mammal prey and, therefore, may also have adopted silent hunting strategies similar to some of the Northern Hemisphere mammal-eating killer whales (e.g., Deecke et al., 2005). This may have significant implications for the probability of acoustic detection, which may differ substantially between the different ecotypes. Even if reliable ecotypespecific acoustic markers can be identified, the reliability of acoustic presence as an indicator of the presence of mammal-eating killer whales warrants further investigation and needs to be taken into account when compiling PAM-mediated distribution data of Antarctic killer whales.

Call Segments-Nearly two thirds of all call types were found to start with a short broadband pulse. Two of the seven call types observed by Richlen \& Thomas (2008) also started with a similar short broadband pulse. Behavioural records providing information on the context in which these sounds were produced by the Ecotype C killer whales are lacking due to the opportunistic nature of data collection during both encounters and the fact that the animals were too far from the observers to see detailed behaviour. However, the prevalence of this acoustic feature and its potential as an ecotype-specific acoustic marker deserves further investigation once further Ecotype $\mathrm{C}$ data and comparative data from other ecotypes become available.

Acoustic Complexity - The identified call types were all characterized by their overall acoustic complexity and high variability in the extent of frequency modulation (see Supplementary Figure ES2 in the Supplementary Materials) for three examples of calls with different extents of frequency modulation). The latter could indicate different levels of excitement as has been suggested for other killer whale populations (Ford, 1989; Rehn et al., 2011). However, some call types exhibited a combination of modulated and unmodulated segments (e.g., call types 2 and 7), suggesting that frequency modulation might have a concrete function in information transmission. The strength of frequency modulation in specific segments, therefore, may be something that is deliberately implemented by the animal to serve a communicative function. Four of the seven call types in the call repertoire identified by Richlen \& Thomas (2008) for one of the Antarctic killer whale ecotypes also exhibited this characteristic frequency modulation pattern. Although the acoustic complexity of the overall repertoire is a feature that is more difficult to quantify, it might be a valuable overall characteristic that can help distinguish between ecotypes acoustically. However, further data are necessary to explore this possibility in more detail.

The call repertoire included a relatively high number of biphonic call types, which also occurred considerably more often in the recordings than monophonic calls. In Pacific and Atlantic fisheating killer whales, usage of these call types was shown to be related to the number of pods in the area, with biphonic calls used more often when more than one pod was present, whereas monophonic calls dominated when a single pod was present (Foote et al., 2008; Filatova et al., 2009). Therefore, it has been suggested that group composition influences the complexity of calls. However, to date, nothing is known about the social structures of Antarctic killer whales. It also remains unknown if Ecotype $\mathrm{C}$ killer whales are organized in stable groups comparable to the Northern Hemisphere fish-eating killer whale matrilineal pods. The underwater habitat of Antarctic killer whales is more variable with respect to the prevalence of sea ice and potential consequences for prey availability compared to many of the Northern Hemisphere fish-eating killer whale habitats (e.g., Nicol et al., 2000). It cannot be excluded that this may require more flexibility in killer whale social organization - for example, promoting fission and fusion of groups, which also would have consequences for the organization of acoustic behaviour. 


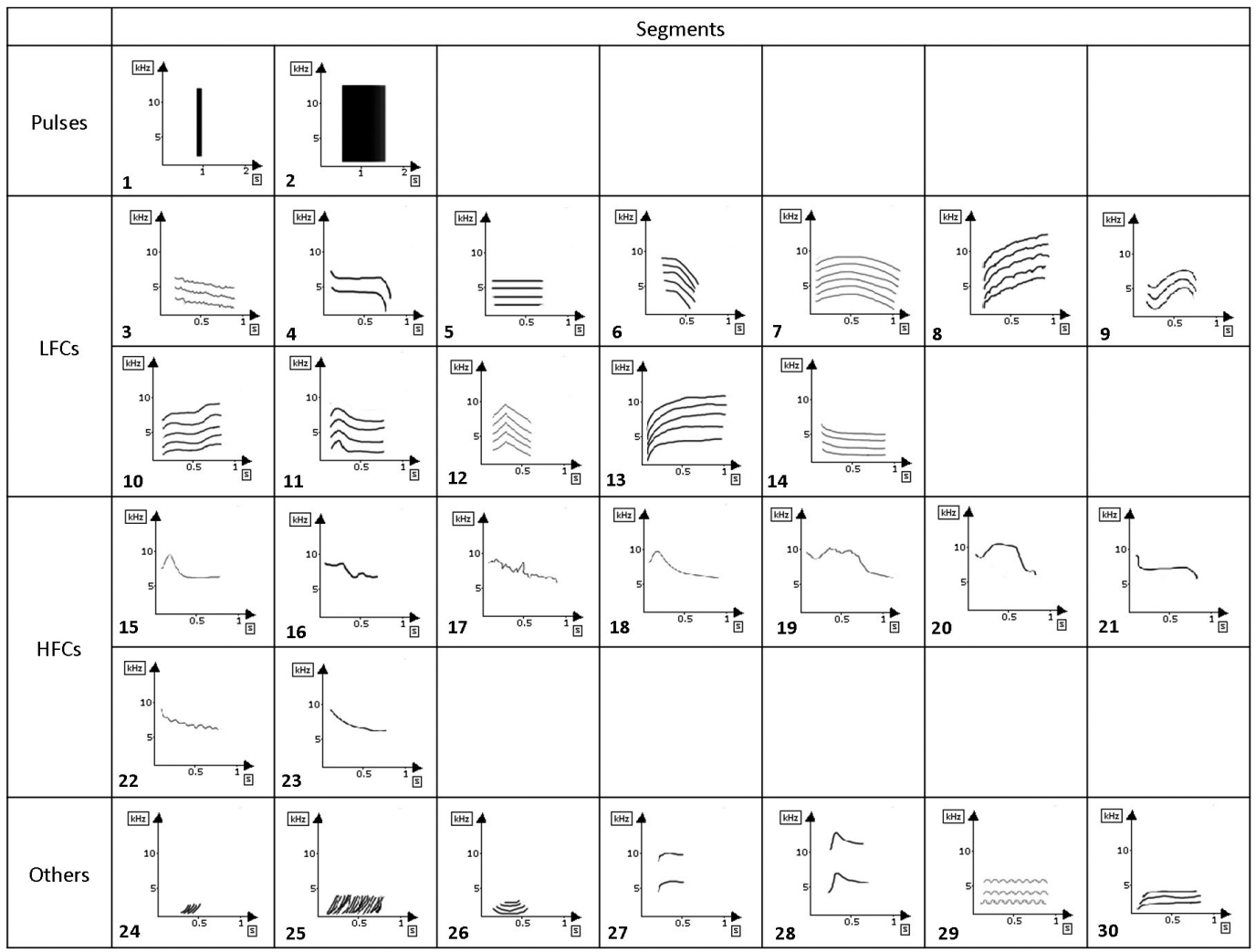

Figure 5. All 30 call segments found in the 26 call types from Antarctic Ecotype C killer whales, divided into pulses, lowfrequency components (LFCs), high-frequency components (HFCs), and "Others"

Alternatively, the comparatively frequent use of biphonic call types may reflect an adaptation of Antarctic killer whales to local ambient noise conditions. Biphonation has been suggested to increase the likelihood that a signal is detected and recognized by a receiver (Wilden et al., 1998; Filatova et al., 2009). Off the Eckström Iceshelf, seasonal sea-ice break-up typically occurs between January and March, causing ambient noise levels to be generally higher compared to the rest of the year (Menze, 2012). By using two independently modulated call components, the probability that a call is detected may be actively enhanced.

\section{Classification}

The killer whale call types described herein were characterised by a relatively high within-calltype variability. This together with relatively low signal-to-noise ratios significantly complicated the classification into distinct call types. Classification of calls through human observers is still the most reliable and most commonly applied method in bioacoustic studies but involves certain disadvantages such as reduced reproducibility and no clearly defined threshold values for classification (Janik, 1999).

For complex multi-segment calls, such as the killer whale calls described herein, classification based on call segments instead of the overall call signature may provide a more stable basis to describe the vocal repertoire that is less prone to subjectivity and, hence, can be more easily replicated (Shapiro et al., 2011). Segment-based call classification has the further advantage that it can be based on a smaller number of discrete call segments necessary to describe all killer whale calls (discrete as well as variable and aberrant calls). Applied to the call types of the Antarctic Ecotype C killer whales identified in this study, calls consist of 30 distinct subsegments in four classes: (1) two different broadband pulse-segments, (2) 12 different LFCs, (3) nine HFCs, and (4) seven categorized as "Others" (Figure 5).

Given the importance of reproducibility and objectivity of call type classification in the context of exploring for ecotype-specific acoustic 
markers, we recommend segment-based classification as the fundament for future studies.

\section{Acknowledgments}

We thank Lars Kindermann for coordinating acquisition of the passive acoustic and photographic data, and the 2012 and 2013 overwintering teams at Neumayer Station III who collected the photos of the Ecotype C killer whales off PALAOA. We also thank Diego Filún Hernández and Stephanie Czudaj for assistance with the acoustic analyses, and Olaf Boebel for providing constructive comments to the manuscript. The logistics department of the Alfred Wegener Institute for Polar and Marine Research, Bremerhaven, Germany; Reederei F. Laeisz GmbH, Rostock, Germany; and FIELAX Services for Marine Science and Technology $\mathrm{GmbH}$, Bremerhaven, Germany, all played a crucial role in setting up and/or maintaining PALAOA.

\section{Literature Cited}

Ainley, D. G., Ballard, G., \& Olmastroni, S. (2009). An apparent decrease in the prevalence of "Ross Sea killer whales" in the southern Ross Sea. Aquatic Mammals, 35(3), 335347. https://doi.org/10.1578/AM.35.3.2009.335

Andrews, R. D., Pitman, R. L., \& Ballance, L. T. (2008). Satellite tracking reveals distinct movement patterns for type B and type C killer whales in the southern Ross Sea, Antarctica. Polar Biology, 31(12), 1461-1468. https://doi.org/10.1007/s00300-008-0487-z

Awbrey, F. T., Thomas, J. A., Evans, W. E. , \& Leatherwood, S. J. (1982). Ross Sea killer whale vocalizations: Preliminary description and comparison with those of some northern hemisphere killer whales. Report of the International Whaling Commission, 32, 667-670.

Barrett-Lennard, L. G., Ford, J. K. B., \& Heise, K. A. (1996). The mixed blessing of echolocation: Differences in sonar use by fish-eating and mammal-eating killer whales. Animal Behaviour, 51(3), 553-565. https://doi. org/10.1006/anbe.1996.0059

Bioacoustics Research Program. (2011). Raven Pro: Interaction sound analysis software (Version 1.4) [Computer software]. Ithaca, NY: The Cornell Lab of Ornithology. Available from www.birds.cornell.edu/ raven

Chariff, R. A., Ponirakis, D. W., \& Krein, T. P. (2006). Raven Lite 1.0 user's guide. Ithaca, NY: The Cornell Lab of Ornithology.

Deecke, V. B., Ford, J. K. B., \& Slater, P. J. (2005). The vocal behaviour of mammal-eating killer whales: Communicating with costly calls. Animal Behaviour, 69(2), 395-405. https://doi.org/10.1016/j.anbehav.2004. 04.014

Deecke, V. B., Nykänen, M., Foote, A. D., \& Janik, V. M. (2011). Vocal behaviour and feeding ecology of killer whales (Orcinus orca) around Shetland, UK. Aquatic Biology, 13, 79-88. https://doi.org/10.3354/ab00353

Filatova, O., Fedutin, I., Nagaylik, M., Burdin, A., \& Hoyt, E. (2009). Usage of monophonic and biphonic calls by free-ranging resident killer whales (Orcinus orca) in Kamchatka, Russian far east. Acta Ethologica, 12(1), 37-44. https://doi.org/10.1007/s10211-009-0056-7

Filatova, O., Guzeev, M., Fedutin, I., Burdin, A., \& Hoyt, E. (2013). Dependence of killer whale (Orcinus orca) acoustic signals on the type of activity and social context. Biology Bulletin, 40(9), 790-796. https://doi.org/ 10.1134/S1062359013090045

Foote, A. D., Osborne, R. W., \& Hoelzel, A. R. (2008). Temporal and contextual patterns of killer whale (Orcinus orca) call type production. Ethology, 114(6), 599-606. https://doi.org/10.1111/j.1439-0310.2008.01496.x

Ford, J. K. B. (1987). A catalogue of underwater calls produced by killer whales (Orcinus orca) in British Columbia. Nanaimo, BC: Department of Fisheries and Oceans, Fisheries Research Branch, Pacific Biological Station.

Ford, J. K. B. (1989). Acoustic behaviour of resident killer whales (Orcinus orca) off Vancouver Island, British Columbia. Canadian Journal of Zoology, 67(3), 727-745. https://doi.org/10.1139/z89-105

Ford, J. K. B. (1991). Vocal traditions among resident killer whales (Orcinus orca) in coastal waters of British Columbia. Canadian Journal of Zoology, 69(6), 14541483. https://doi.org/10.1139/z91-206

Gedamke, J., Costa, D. P., \& Dunstan, A. (2001). Localization and visual verification of a complex minke whale vocalization. The Journal of the Acoustical Society of America, 109(6), 3038-3047. https://doi.org/ $10.1121 / 1.1371763$

Hoelzel, A. R., \& Osborne, R. W. (1986). Killer whale call characteristics: Implications for cooperative foraging strategies. In B. Kirkevold \& J. Lockard (Eds.), Behavioral biology of killer whales (Zoo Biology Monographs, Vol. 1, pp. 373-403). New York: Alan R. Liss. 457 pp.

Holt, M. M., Dunkin, R. C., Noren, D. N., \& Williams, T. M. (2013). Are there metabolic costs of vocal responses to noise in marine mammals? Proceedings of Meetings on Acoustics, 19(1), 010060. https://doi. org/10.1121/1.4800971

Janik, V. M. (1999). Pitfalls in the categorization of behaviour: A comparison of dolphin whistle classification methods. Animal Behaviour, 57(1), 133-143. https://doi. org/10.1006/anbe.1998.0923

Klinck, H., Kindermann, L., \& Boebel, O. (2016). PALAOA: The PerenniAL Acoustic Observatory in the Antarctic Ocean-Real-time eavesdropping on the Antarctic underwater soundscape. In W. W. L. $\mathrm{Au} \&$ M. O. Lammers (Eds.), Listening in the ocean (pp. 207-219). New York: Springer. https://doi.org/ 10.1007/978-1-4939-3176-7_8

McCreery, L., \& Thomas, J. A. (2009). Acoustic analysis of underwater vocalizations from crabeater seals 
(Lobodon carcinophagus): Not so monotonous. Aquatic Mammals, 35(4), 490-501. https://doi.org/ 10.1578/AM.35.4.2009.490

Menze, S., Zitterbart, D. P., van Opzeeland, I., \& Boebel, O. (2016, In press). The influence of sea ice, wind speed and marine mammals on Southern Ocean ambient sound. Royal Society Open Science.

Nicol, S., Pauly, T., Bindoff, N. L., Wright, S., Thiele, D., Hosie, G. W., . . Woehler, E. (2000). Ocean circulation off east Antarctica affects ecosystem structure and seaice extent. Nature, 406(6795), 504-507. https://doi.org/ $10.1038 / 35020053$

Pitman, R. L., \& Ensor, P. (2003). Three forms of killer whales (Orcinus orca) in Antarctic waters. Journal of Cetacean Research and Management, 5(2), 131-140.

Pitman, R. L., Durban, J. W., Greenfelder, M., Guinet, C., Jorgensen, M., Olson, P. A., . . . Towers, J. R. (2011). Observations of a distinctive morphotype of killer whale (Orcinus orca), type D, from subantarctic waters. Polar Biology, 34(2), 303-306. https://doi.org/ 10.1007/s00300-010-0871-3

Rehn, N., Filatova, O. A., Durban, J. W., \& Foote, A. D. (2011). Cross-cultural and cross-ecotype production of a killer whale "excitement" call suggests universality. Naturwissenschaften, 98(1), 1-6. https://doi.org/ 10.1007/s00114-010-0732-5

Rettig, S., Boebel, O., Menze, S., Kindermann, L., Thomisch, K., \& van Opzeeland, I. (2013). In J. Papadakis \& L. Bjorno (Eds.), Local to basin scale arrays for passive acoustic monitoring in the Atlantic sector of the Southern Ocean. Corfu Island, Greece. 1,686 pp. ISBN 978-618-80725-0-3

Richlen, M. F., \& Thomas, J. A. (2008). Acoustic behaviour of Antarctic killer whales (Orcinus orca) recorded near the ice edge of McMurdo Sound, Antarctica. Aquatic Mammals, 34(4), 448-457. https://doi.org/ 10.1578/AM.34.4.2008.448

Riesch, R., \& Deecke, V. B. (2011). Whistle communication in mammal-eating killer whales (Orcinus orca): Further evidence for acoustic divergence between ecotypes. Behavioral Ecology and Sociobiology, 65(7), 1377-1387. https://doi.org/10.1007/s00265-011-1148-8

Risch, D., Gales, N. J., Gedamke, J., Kindermann, L., Nowacek, D. P., Read, A. J., . . . Friedlaender, A. S. (2014). Mysterious bio-duck sound attributed to the Antarctic minke whale (Balaenoptera bonaerensis). Biology Letters, 10(4), 20140175. https://doi. org/10.1098/rsbl.2014.0175

Shapiro, A. D., Tyack, P. L., \& Seneff, S. (2011). Comparing call-based versus subunit-based methods for categorizing Norwegian killer whale, Orcinus orca, vocalizations. Animal Behaviour, 81(2), 377-386. https://doi. org/10.1016/j.anbehav.2010.09.020

Širović, A., Hildebrand, J. A., Wiggins, S. M., McDonald, M. A., Moore, S. E., \& Thiele, D. (2004). Seasonality of blue and fin whale calls and the influence of sea ice in the western Antarctic peninsula. Deep Sea Research
Part II: Topical Studies in Oceanography, 51(17), $2327-$ 2344. https://doi.org/10.1016/j.dsr2.2004.08.005

Strager, H. (1995). Pod-specific call repertoires and compound calls of killer whales, Orcinus orca Linnaeus, 1758 , in the waters of northern Norway. Canadian Journal of Zoology, 73(6), 1037-1047. https://doi. org/10.1139/z95-124

Van Opzeeland, I., Kindermann, L., Boebel, O., \& Van Parijs, S. (2008). Insights into the acoustic behaviour of polar pinnipeds - Current knowledge and emerging techniques of study. In E. A. Weber \& L. H. Krause (Eds.), Animal behaviour: New research (pp. 133-161). Hauppage, NY: Nova Science Publishers.

Van Opzeeland, I., Corkeron, P. J., Leyssen, T., Similä, T., \& Van Parijs, S. M. (2005). Vocal behaviour of Norwegian killer whales, Orcinus orca, during carousel and seiner foraging on spring-spawning herring. Aquatic Mammals, 31(1), 110-119. https://doi.org/10.1578/ AM.31.1.2005.110

Van Opzeeland, I., Van Parijs, S., Kindermann, L., Burkhardt, E., \& Boebel, O. (2013). Calling in the cold: Pervasive acoustic presence of humpback whales (Megaptera novaeangliae) in Antarctic coastal waters. PLOS ONE, 8(9), e73007. https://doi.org/10.1371/journal.pone. 0073007

Van Parijs, S. M., Clark, C. W., Sousa-Lima, R. S., Parks, S. E., Rankin, S., Risch, D., \& Van Opzeeland, I. (2009). Management and research applications of real-time and archival passive acoustic sensors over varying temporal and spatial scales. Marine Ecology Progress Series, 395 , 21-36. https://doi.org/10.3354/meps08123

Wellard, R., Erbe, C., Fouda, L., \& Blewitt, M. (2015). Vocalisations of killer whales (Orcinus orca) in the Bremer Canyon, Western Australia. PLOS ONE, 10(9), e0136535. https://doi.org/10.1371/journal.pone.0136535

Wilden, I., Herzel, H., Peters, G., \& Tembrock, G. (1998). Subharmonics, biphonation, and deterministic chaos in mammal vocalization. Bioacoustics, 9(3), 171-196. https://doi.org/10.1080/09524622.1998.9753394 